\title{
EMPIRICAL INVESTIGATION OF FACTORS THAT IMPACT E-GOVERNMENT ADOPTION IN NIGERIA
}

\author{
Joshua Chukwu, Marc Conrad and Tess Crosbie \\ University of Bedfordshire, Luton Campus, UK
}

\begin{abstract}
This paper is a review of the impact of data protection/privacy, website usability and culture on e-government adoption. Along with Hofstede's cultural dimensions and technology acceptance theory, the paper uses these two theories to analyse the highly anticipated era of electronic government, an aspect through which government communicates with agencies and business organisation through information communication technology. We examine the adoption process, its challenges and difficulties, especially in developing countries like Nigeria considering fundamental deficiencies in basic infrastructure, human capacity, political and cultural constraints. This paper can help Nigerian government policy and decision makers develop strategies to adopt e-government services and improve the further development of these services. The paper does not only provide empirical support to previous research, but it validates and improve the results of similar studies in the field.
\end{abstract}

\section{KEYWORDS}

e-Government, Usability, Culture, Adoption, Nigeria, Data Protection/Privacy, Technology Acceptance, Hofstede

\section{INTRODUCTION}

E- Government is a driving force that has the power to shape public policies at a global level, at time when both political and business leaders around the world are embracing e-government leadership that can be seen working effectively in public and private sectors (Ciborra 2009). The electronic approach dwells on the integration of different public services and other organisational functions, some examples are e-payment, e-learning, e-security, and e-commerce (Carter and Belanger, 2005). The implementation of e-government ensures productive relationships between the government and other stakeholders such as government agencies, citizens and business organisations (Mundy and Musa 2010; UN 2018). According to Ciborra (2009), e-government is a significant reason policy reform is taking place in public sectors around the world. However, it appears to be difficult for developing countries to conceptualise a situation where all government activities and interaction can be done through one platform 24 hours a day and seven days a week without going through a third party or waiting in lines or bribing someone (Dada, 2006). UN e-government Survey (2018) found that Nigeria is ranked 143 in the world out of 192 countries in terms of e-government, that is, since 2016 there has not been any change. The e-participation index which highlights the degree of application of ICT and participation by governments to enhance their services have seen a constant reduction of -42 since 2012 when Nigeria was ranked 75. Several studies have revealed that culture is a major factor as it affects both data protection/ privacy and e-government usability. This paper seeks to understand how culture impact e-government adoption, the influence of data protection/privacy and website usability on Nigerians. To answer this question, we will refer to Hofstede dimension theory and technology acceptance will be used to examine the correlation between culture and E-government adoption. Four out of six Hofstede dimension will be used (power distance, individualism, short term orientation and uncertainty avoidance). The reason behind this is that the rest of the dimensions have no direct impact on technology acceptance used to analyse e-government in Nigeria in this paper. 


\section{RELATED WORK}

\section{1 e-Government Adoption}

The application of information communication technology is transforming government services in terms of speed, accuracy and efficiency (Atzori et al., 2010). In the view of Kumar et al. (2007) and Ciborra (2009), the transformation is the reason both the public sector and organisations are reforming their policies. More so, Gubbi et al. (2013) believe that various government organisations have realised the benefits of e-government, hence want to leverage it to offer citizens easy access to government information and increase the quality of government services. There is a push at various government levels to adopt electronic means of providing government services to citizens. It is an agenda of many governments in Africa to benefit from this technology in order to replace paperwork with electronic means for effectiveness and quality service delivery to citizens (Lee, Chang and Berry 2011; UN, 2018). However, E-government initiatives look very promising but appears to be difficult to implement in developing countries like Nigeria (Dada, 2006), According to a substantial study by Heeks (2002), most implementations of e-government projects in developing countries fail with $35 \%$ considered total failure and $50 \%$ abandoned as a result of undesired results. On the other hand, some other countries like South Korea, Austria, New Zealand and the Netherlands are doing well in e-government services (Stier, 2015). e-government adoption as research is fragmented. However, recent studies are beginning to use theories to explore major factors that impact e-government adoption, the importance of this technique is that the integration of theories can correct the limitation of an individual approach (Carter and Belanger, 2005). The theory of e-government adoption according to Gilbert et al., (2004) characterised attitude based on the design of diffusion of innovation theory and Theory of Reason Action in relation to service quality using Technology acceptance model. This approach is supported by behavioural theory which has direct impact on user intention. The theory variable is dependent on the willingness of citizens to use e-government services. The perceived usefulness includes the reducing physical contact, cost, time and convenience. Its disadvantages are the lack of usability, reliability, data protection/privacy and ease of use. (Davis 1989).

\section{2 e-Government in Developing Countries}

According to the recently concluded UN e-government survey 2018, none of the African countries emerged in the top 50 of the e-government development global index (UN 2018). To understand these factors that impact e-government adoption, Colesca (2009) proposes a model which has a solution to reduce e-government related risk. The model is characterised with determinant of trust in e-government such as perceived usefulness, perceived quality, risk perception, trust in technology, privacy concern and education. Her recommendation revealed that a younger generation is more responsive to e-government than the older generation. Lean et al. (2009) emphasised that technological acceptance and diffusion of innovation theory can be used to capture individual perception of technology. This framework was used to analyse factors influencing user's intention on e-government services in Malaysia. The findings suggest that perceived usefulness, perceived relative advantage have more impact on citizens towards using e-government. However, these models have mixed variables and are really narrow in their scope, they tend to focus on limited factors impacting e-government adoption. Few researchers have considered data protection/privacy, website usability and culture in their proposed frameworks. The overall benefits of e-government are enormous, it is not just Government to citizen, Government to Government transactions, but also efficiency and effectiveness in government service delivery (Jaeger 2003). The recently concluded UN e-government survey 2018 emphases that transparency and accountability of government business improve utilisation and enhances the democratisation process. Nevertheless, e-government initiatives represent a high risk for developing countries. There are risks of digital a divide and marginalisation for countries that fail to embrace information communication technology tools for entering the global market and addressing development needs (Ndou, 2004). However, according to Heeks (2002), the potential benefit of e-government includes reduction in corrupt practices, electronic means of communication, equal opportunity and elimination of bureaucratic governance. 


\section{DEFINITIONS AND RELEVANT FACTORS}

\section{1 e-Government Definition}

United Nations (2018) defines e-government as the use of information technology by government organisations and agencies to provide effective electronic interaction, transaction and exchange of information between the government and the citizen. The World Bank sees e-government as a process of implementing cost-effective models for citizens, government organisations, agencies and other stakeholders to transact business online and access government information (World Bank, 2017). Fang (2002) proposed that e-government is a transformation of public sector internal and external relationships with electronic means in order to effectively improve government service delivery. Halchin (2004) argues that e-government lacks a comprehensive definition that is accepted globally. However, the use of information systems to improve the effectiveness and efficiency in delivering government services constitutes the concept of e-government. Ihmouda et al. (2014) and Ihmouda and Alwi (2006) see e-government as a form of the structure through which government information is delivered electronically to the public, which could either be the citizens or businesses organisations. The various e-Government types are government to citizens (G2C), Government to business (G2B), Government to employee (G2E) and Government to Government (G2G). From the recently concluded UN e-government survey 2018, we can observe that after 2 years Nigeria ranking is still in one position. The study of Dada (2006) concluded that the degree of e-government adoption in developing countries like Nigeria is driven by individual government and not a long-term government system. The projects are presented as political evidence. The political nature makes e-government adoption in Nigeria slow and often abandoned (Heeks 2002). It also shows that Nigeria is not among the top ten countries on the Africa e-government global development index. Several studies have revealed that culture is a major factor as it affects both data protection/ privacy and e-government usability. The following section discusses in detail the factors as they relate to e-government adoption in Nigeria.

\subsection{Hofstede}

The six-dimension theory developed by Geert Hofstede is a model that explains different culture across countries, suggesting pattern of business carried out in different cultures. The framework differentiates between different national cultures, their dimensions and impacts on the members of the society (Hofstede 2001). Hofstede (2001), defines culture as a collective way of life, beliefs that differentiate a group of people from another. Different theories try to analyze cultural differences (Dickson et al., 2003; Inglehart and Welzel, 2005) but among them Hofstede six dimension is the most widely used. This is despite criticism of Hofstede theory by Baskerville (2005) who reveals various disparity in both theory and methodology, hence caution researchers against unfussy reading of Hofstede's cultural dimensions. The assumption of equating nations with culture and the status of the observers outside the culture was criticised by Baskerville (2005). However, Hofstede's approach appears to be relevant as it involves the West African region which includes Nigeria and is well cited within the technology acceptance domain (Hasan and Dista, 1999). Nigeria has an average score of $55 \%$ uncertainty avoidance, $80 \%$ on power distance, $30 \%$ on individualism, $13 \%$ on long term orientation and $60 \%$ on masculinity. The six dimensions shows substantial diversity within citizens in a particular country and similarities among people from a different country (Hofstede, 1983). In this paper, we will limit our study to four out of six Hofstede dimensions (power distance, individualism, short-term orientation and uncertainty avoidance) as these are directly relevant to the adoption of e-government.

\subsubsection{Power Distance}

Power distance index is used to measure the extent to which a particular society or members of an organisation accept equal distribution of power. In countries with high power distance, leaders are unquestionable, and they decide what information is to be shared with the public (Hofstede and Hofstede, 2005). Countries with a high score of power distance struggle with innovative technology because technology appears as a threat to bureaucratic and corrupt leadership.

\subsubsection{Uncertainty Avoidance}

Uncertainty avoidance deals with cultural values on future predictability. According to Hofstede and Minkov (2005), it is the magnitude to which members of a culture feel vulnerable to unknown situations. Nigeria has an average score of $55 \%$ on Uncertainty Avoidance which does not show a clear preference (Hofstede, 2005). 


\subsubsection{Individualism/ Collectivism}

Individualism versus collectivism is a dimension that represents personal decision against integrated groups. Personal differences do not matter as people tend to seek for freedom to practice and do what they like without control. Cultures high on individualism promote personal decision over group. (Hofstede and Minkov 2005). Nigeria is considered a collectivistic country (Hofstede, 2005), where people are loyal to each other and tend to be in groups.

\subsubsection{Short/Long Term Orientation}

According to Hofstede (2005), term orientation is classified into short-term and long-term orientation of people in a particular society, this dimension represents some characteristics of social and ethical philosophy (Gong et al. 2007). Every long-term oriented culture is characterised by values with priority for the future goal and result. With respect to technology acceptance, members from a short orientation cultural structure are associated with immediate perceived usefulness.

\subsection{Technology Acceptance (TAM)}

According to Davis (1989), TAM suggests that Behavioural intention of an individual depends on the attitude towards the behaviour. It is measured with two major factors.

\section{Perceived Usefulness (PU)}

This refers to the degree to which an individual believes that the use of a particular technology would enhance his or her job performance.

\section{Perceived Ease of Use (PEOU)}

Davis refers to this as the degree to which an individual believes that the use of a particular technology would be free from personal effort.

TAM explains user acceptance of information system technology with clearer understanding on various behaviour surrounding technology acceptance (Shareef, 2011). The model has been cited by thousands of professionals in the information system field and has demonstrated its effectiveness beyond organisational and geographical contexts. Surendran (2012) linked TAM and information behavioural model to explain the relevance of an information system. Also, Pikkarainen et al. (2004) used TAM to understand the acceptance of online banking in Finland and the role played by perceived usefulness in online banking.

\subsection{Usability}

"In a fair society, all individuals would have equal opportunity to participate, or benefit from the use of computer resources regardless of race, sex, religion age, disability, national origin or other similar factor" (Shneideerman, 2000). Buie and Murrary (2012) state that usability is the capacity to communicate, learn and use new products and services and obtain a positive result. According to Gant et al. (2002) and Casalo et al. (2005) Usability demonstrates how easily users can access and navigate government websites. Some research work believes that this demonstration depends on different features of usability such as effectiveness, efficiency, satisfaction, learnability, error tolerance and memorability (Nielsen, 2006; Abran et al., 2003; Casalo et al., 2008).

\section{APPLYING HOFSTEDE AND TAM TO THE CASE OF NIGERIA}

\subsection{Data Protection and Privacy in Nigeria}

Data protection and privacy concerns, according to Wimmer and Bredow (2002), are Secured transactions, protection against unauthorised access to government information, major attacks from hackers. The sharing of government information in real-time has increased the popularity of e-government since it has been used to break administrative barriers and enable citizens to have access to government information from the 
comfort of their home. However, it has created a major security challenge (Hui and Hayllar, 2010). Data protection is a security process of safeguarding important information from corruption, compromise or loss. The UN e-government survey report (2018), emphasised that privacy is a great influence on e-government adoption. Small and big business organisations in Nigeria recognise this challenge in their electronic transaction services (Okifo and Igbunu, 2015). In the Nigerian perceptive it is a right and control over their information according to the Constitution (1999), as amended. However, the right of privacy stated in section 37 of the Nigerian 1999 constitution does not protect online personal data in this present day of online communication. There is no comprehensive law that provides Nigerians online data protection unlike countries like the United Kingdom, United States of America or Germany that favour a comprehensive regulatory approach to data protection (Aliyu, 2016). Therefore, to achieve data protection and privacy and encourage usability, it is important for the Nigerian Government to reassess data protection/ privacy framework. Given the challenges of online services with the abundance of data, it is essential to reassess and develop effective legal infrastructure for data protection and privacy. After all, e-government is not an automatic solution, rather a combination of technical, social and cultural shifts which need a data protection legal framework. Effort must be made to ensure that people's information is secured and protected (Kesar, 2011).

\subsection{Usability of E-Government Websites in Nigeria}

With reference to Gant et al., (2002) and Casalo et al. (2005), in section 3.4, usability shows the level users can interact and navigate web interphase without difficulties, as well as considering speed and efficiency. A developing country like Nigeria and some other West African countries are confronted with vast gaps between demand and supply of e-government services. (Adeyemo 2011; and Moon, 2002) revealed that insufficient development of e-government results in failing to meet users' real needs and expectations. Full e-government adoption depends on its usability according to Chan et al., (2018), citing Nielsen's research work on user's behaviour on the web. Sometimes users give time to observe if the website is slow with download time or have an unstable design, or it takes users few times to understand the function of a website and decide how it will meet their needs. However, the basic element relevant to users is the ability of the website to solve their problems effectively (Thompson, 2003). Users will abandon a website and consider it unusable when it cannot solve their problems. Therefore, using a case study in Kenya on e-government website user experience, e-government Usability in Nigeria can overcome barriers like bureaucratic processes, lack of accountability and transparency, digital division, poor management and legal barriers (Kamau et al., 2016).

\subsection{Technology Acceptance and Hofstede in Nigeria}

As referenced in this paper, Hofstede's dimension theory has been used to measure and quantify Nigerian culture, values and behavioural pattern. In our review, we used Hofstede four of dimension's which were developed from the concept of IBM as well as his estimation for countries that were not in the IBM survey (Hofstede, 2001). The four dimensions are power distance, uncertainty avoidance, individualism-collectivism, and short/long term orientation. Each of these represent a cluster of related values. According to Al-adawi et al., (2005), who extended the TAM model by identifying factors that improve citizen trust and reduce risk in e-government, e-government adoption in Nigerian lacks confidence in the infrastructure of the internet especially with the regular outcry of problems of data protection/privacy, online fraud and security attacks. These factors directly affect behavioural intention to use e-government (Ridwan 2015). Some countries place different values on e-Government adoption, although national culture is seen as a major factor that affects the acceptance of e-Government but research in this direction appears to be limited (Zhao 2011). The possible impact of Hofstede's dimension theory on e-Government can be analysed through the characteristics and interaction of TAM.

\subsubsection{Power Distance}

According to Hofstede (2005), Nigeria has a score of 80 for this dimension compared United Kingdom with (35), Germany (35), and Austria as low as (11). Heeks, (2005) emphasised that even when a new technology is adopted the people in power still control the system and they determine what information to be shared. Using Hofstede dimensions theory, Nigerian culture is characterised by a high level of power distance (Hofstede, 2005), people respect leaders and tend to accept hierarchy which makes followers loyal to their 
leaders. The culture encourages obedience. People grow up in an atmosphere of not questioning their leaders. However, despite the level of power distance in Nigeria culture, citizens accept e-government services based on perceived ease of use and perceived Usefulness (Shareef, 2011). The acceptance of e-government services contradicts Hofstede dimensions in the Nigerian context. The behavioural intention is based on technology acceptance (Zhao 2011).

\subsubsection{Uncertainty Avoidance}

Uncertainty avoidance is a cultural determinant of e-government adoption, and it decides how convenient citizens see e-government services. According to Hofstede and Minkov (2005), it is the magnitude to which members of a society feel vulnerable by an unknown situation. In a high uncertainty avoidance society, people are generally more resistant to innovations, risk-averse and less responsive to change (Gong et al., 2007). The bureaucratic system in Nigeria makes individuals consider e-government services an option to eliminate prolonged delays and third-party system that has to do with a traditional applicational process of government services; e-government services are appreciated in Nigeria with an average score of $55 \%$ on uncertainty avoidance index.

\subsubsection{Individualism Versus Collectivism}

Individualism describes the relationship between groups and individuals. In a low collectivism society, people are concerned about themselves (Gong et al., 2007). In Nigerian context where collectivism is high, people use the group as a primary source for approval and support; this predisposes a culture that rejects innovations like e-government because online services could stop the group's face to face interactions (Hofstede and Minkov 2005). Reviews from the researchers (Gong et al., 2007; Kovacic, 2005; Bagchi et al., 2004) argue that ICT adoption is high among individualistic cultures because the members of an individualistic society have more freedom to express themselves and try new things base on their own opinion. On the other hand, in a collectivistic society, an individual depends on group approval (Gong et al., 2007; Kovacic, 2005). Therefore, everyday features of information technology, such as social media platforms, internet mails and phones calls, are perceived as a threat to face-to -face interaction by members in collective society like Nigeria (Bagchi et al., 2004).

\subsubsection{Short-term Orientation}

According to Hofstede (2005) as a result of short-term orientation culture, people's perception towards e-government results tend to be different. This dimension is about the traditional cultural values and how society members relate with their past and future (Gong et al., 2004; Erumban and Jong 2006). Cultures with short term orientation like Nigeria are characterised by immediate benefits and quick results; more attention is given to past events and traditional stability. Gong et al. (2007) consider long term orientation society to be characterised by persistence and perseverance. They are more focused on future occurrences, and this makes them preserve the importance of long-term benefits of ICT.

\section{RECOMMENDATIONS AND CONCLUSION}

Our novel approach to contextualise Hofstede's six dimensions with TAM shows that culture has a direct impact on data protection/privacy and e-government Usability in Nigeria. Some of the points are as follow: firstly, to ensure e-government adoption government needs to take a citizen-centric approach to understand the cultural values that support technology acceptance. In Nigerian society, culture can influence values and expectations of people in accepting e-government. Secondly, it is paramount to put in place a legal framework to enhance online data protection/privacy. Addressing the issue of e-government through legal framework is critical not only to safeguard online transactions, but also to encourage e-government service usability.

This paper has shown that understanding cultural impact, and good legal formulation for data protection/ privacy are enablers of e-government adoption in Nigeria as well as Government website usability. Using Hofstede's dimensions and TAM within the context of e-government adaption we recommend the reassessment and development of effective legal infrastructure for data protection in Nigeria as the most suitable way forward. As there is an indication of partial failure of e-government adoption already it requires an immediate addressing following the understanding of cultural characteristics of technology acceptance 
used in the study. Further research will focus on how national culture delays e-government adoption specifically and how the legal framework can be implemented.

\section{REFERENCES}

Abran, A., Khelifi, A., Suryn, W. \& Seffah, A. (2003). "Usability Meanings and Interpretations in ISO Standards". Software Quality Journal, Volume 1(4), pp. 325-338.

Adeyemo, A.B., (2011). E-government implementation in Nigeria: An assessment of Nigerias global e-gov ranking. Journal of Internet and Information Systems, 2(1), pp.11-19.

Al-adawi, Z., Yousafzai, S. and Pallister, J., (2005), September. Conceptual model of citizen adoption of e-government. In The Second International Conference on Innovations in Information Technology (IIT'05) (pp. 1-10).

Aliyu, A.S., (2016). The Nigeria Data Protection Bill: Appraisal, Issues, and Challenges. Peer-reviewed academic journal Innovative Issues and Approaches in Social Sciences, p.1961.

Atzori, L., Iera, A. and Morabito, G., (2010). The internet of things: A survey. Computer networks, 54(15), pp .2787-2805.

Bagchi, K., Hart, P. and Peterson, M.F. (2004) National culture and information technology product adoption. Journal of Global Information Technology Management, 7(4), pp.29-46.

Baskerville-Morley, R.F., (2005). A research note: the unfinished business of culture. Accounting, Organizations and Society, 30(4), pp.389-391.

Buie, E. and Murray, D. eds., (2012) Usability in government systems: User experience design for citizens and public servants. Elsevier

Carter, L. and Bélanger, F., (2005). The utilization of e-government services: citizen trust, innovation and acceptance factors. Information systems journal, 15(1), pp.5-25.

Casaló, L., Flavián, C. and Guinaliú, M. (2005) "The role of accessibility and commitment in the development of an e-government strategy", eGovernment Workshop "05 (eGOV05), Brunel University, West London, UK

Casaló, L.V., Flavián, C. and Guinalíu, M., (2008). The role of satisfaction and website usability in developing customer loyalty and positive word-of-mouth in the e-banking services. International Journal of Bank Marketing, 26(6), pp.399-417

Chan, W., Nasrudin, M.F. and Mohamed, I., (2018). A study on the security impact of the web services implementation in the Malaysian government's online applications. International Journal of Advanced Intelligence Paradigms, 11(1-2), pp.159-175.

Ciborra, C.U., (2009). Interpreting e-government and development: Efficiency, transparency or governance at a distance?. In Bricolage, Care and Information (pp. 90-110). Palgrave Macmillan, London.

Colesca, S.E. (2009) Increasing E-trust: A solution to minimize risk in e-Government adoption. Journal of applied quantitative methods, 4(1).

Dada, D., (2006). The failure of E-government in developing countries: A literature review. The Electronic Journal of Information Systems in Developing Countries, 26(1), pp.1-10.

Davis, F. D., Bagozzi, R. P. and Warshaw, P. R. (1989) 'User acceptance of computer technology: a comparison of two theoretical models'. Management science, 35 (8), pp. 982-1003.

Dickson, M.W., Den Hartog, D.N. and Mitchelson, J.K. (2003), "Research on leadership in a cross-cultural context: making progress, and raising new questions", The Leadership Quarterly, Vol. 14, pp.

Erumban, A.A. and De Jong, S.B. (2006) Cross-country differences in ICT adoption: A consequence of Culture?. Journal of world business

Fang, Z., (2002) E-government in digital era: concept, practice, and development. International journal of the Computer, the Internet and management, 10(2), pp.1-22

Federal Government of Nigeria (1999), Constitution of the Federal Republic of Nigeria 1999.

Gant, J.P and Gant, D.B. (2002) "Web Portal Functionality and State Government E-Services", Proceedings of the 35th Hawaii International Conference on Systems Sciences.

Gong, W., Li, Z.G. and Stump, R.L., (2007) Global internet use and access: cultural considerations. Asia Pacific Journal of Marketing and Logistics, 19(1), pp.57-74.

Gubbi, J., Buyya, R., Marusic, S. and Palaniswami, M., (2013). Internet of Things (IoT): A vision, architectural elements, and future directions. Future generation computer systems, 29(7),

Halchin, L. E. (2004) 'Electronic government: Government capability and terrorist resource'. Government Information Quarterly, 21 (4), pp. 406-419. 
Hasan, H. and Ditsa, G., (1999). The impact of culture on the adoption of IT: An interpretive study. Journal of Global Information Management (JGIM), 7(1), pp.5-15.

Heeks, R., (2002). e-Government in Africa: Promise and practice. Information polity, 7(2, 3), pp.97-114.

Hofstede, G., Hofstede, G.J. and Minkov, M. (2005). Cultures and organizations: Software of the mind (Vol. 2). New York: Mcgraw-hill.

Hui, G. and Hayllar, M.R., (2010). Creating public value in e-Government: A public-private-citizen collaboration framework in Web 2.0. Australian Journal of Public Administration, 69, pp.S120-S131

Ihmouda, R., Alwi, N.H.M. and Abdullah, I., (2006). Successful factors on e-government security social-technical aspect.

Ihmouda, R., Alwi, N.H.M. and Abdullah, I., (2014). A Systematic Review on E-government Security Aspects. International Journal of Enhanced Research in Management and Computer Applications.

Inglehart, R. and Welzel, C. (2005), Modernization, Cultural Change, and Democracy: The Human Development Sequence, Cambridge University Press, New York, NY.

Kamau, G., Njihia, J. and Wausi, A., 2016, May. E-government websites user experience from public value perspective: Case study of iTax website in Kenya. In 2016 IST-Africa Week Conference (pp. 1-8). IEEE.

Kesar, S., (2011), Is cybercrime one of the weakest links in electronic government. J. Int'l Com. L. \& Tech., 6, p.243.

Kovacic, Z.J. (2005) A brave new e-world? An exploratory analysis of worldwide e-government readiness, level of democracy, corruption and globalization. International Journal of Electronic Government Research (IJEGR), 1(3), pp.15-32.

Kumar, V., Mukerji, B., Butt, I. and Persaud, A., (2007). Factors for successful e-government adoption: A conceptual framework. Electronic Journal of E-government, 5(1).

Lean, O.K., Zailani, S., Ramayah, T. and Fernando, Y., (2009). Factors influencing intention to use e-government services among citizens in Malaysia. International Journal of Information Management, 29(6), pp.458-475.

Lee, C.P., Chang, K. and Berry, F.S., (2011). Testing the development and diffusion of e-government and e-democracy: A global perspective. Public Administration Review, 71(3), pp.444-454.

Moon, M. (2002) The Evolution of e-government among municipalities: rhetoric or reality. Public Administration Review 62 (4), 424-33

Mundy, D. and Musa, B., (2010). Towards a framework for egovernment development in Nigeria. Electronic Journal of E-government, 8(2), p.147.

Nielsen, J., Loranger, H. (2006) "Prioritizing web usability", New Riders, Berkeley, California

Ndou, V. (2004). E-government for developing countries: opportunities and challenges. The Electronic Journal on Information Systems in Developing Countries 18 (1), 1-24.

Okifo, J. and Igbunu, R., (2015). Electronic Payment System in Nigeria: Its Economic Benefits and Challenges. Journal of Education and Practice, 6(16), pp.56-62.

Ridwan, S.M., (2015), Electronic Government and the Future of Digital Age: A Road Map of Nigerian Government (Prospects and Challenges). American Scientific Research Journal for Engineering, Technology, and Sciences (ASRJETS), 11(1), pp.42-50.

Saunders, M., Lewis, P. and Thornhill, A., (2009). Research methods for business students. Pearson education

Shareef, M.A., Kumar, V., Kumar, U. and Dwivedi, Y.K., 2011. e-Government Adoption Model (GAM): Differing service maturity levels. Government information quarterly, 28(1), pp.17-35.

Shneiderman, B., (2000). Universal usability. Communications of the ACM, 43(5), pp.84-91

Stier, S., (2015). Political determinants of e-government performance revisited: Comparing democracies and autocracies. Government Information Quarterly, 32(3), pp.270-278.

Thompson, K. M., McClure, C. R. and Jaeger, P. T. (2003) "Evaluating federal websites: Improving eGovernment for the people”, In J. F. George (Ed.), Computers in society: Privacy, ethics, and the Internet, Upper Saddle River, NJ: Prentice Hall.

United Nations Survey (2018). Mobilizing e-government to build resilient societies: Preconditions and enabling environment, New York, pp. 1-25.

Wimmer, M. and Von Bredow, B., (2002), A holistic approach for providing security solutions in e-government. In System Sciences, 2002. HICSS. Proceedings of the 35th Annual Hawaii International Conference on (pp. 1715-1724). IEEE.

World Bank, (2011), Definition of E-Government, [online] available from http://go.worldbank.org

Zhao, F., (2011), Impact of national culture on e-government development: a global study. Internet Research, 21(3), pp.362-380. 